\title{
Diagnostic performance of 320 -slice multidetector computed tomography coronary angiography in patients after coronary artery bypass grafting
}

\author{
Fleur R. de Graaf • Joëlla E. van Velzen • Agnieszka J. Witkowska • \\ Joanne D. Schuijf • Noortje van der Bijl • Lucia J. Kroft • Albert de Roos • \\ Johan H. C. Reiber • Jeroen J. Bax • Greetje J. de Grooth • J. Wouter Jukema • \\ Ernst E. van der Wall
}

Received: 21 February 2011 /Revised: 5 May 2011 / Accepted: 12 May 2011 /Published online: 7 July 2011

(C) The Author(s) 2011. This article is published with open access at Springerlink.com

\begin{abstract}
Objectives To evaluate the diagnostic performance of 320slice computed tomography coronary angiography (CTA) in the evaluation of patients with prior coronary artery bypass grafting (CABG). Invasive coronary angiography (ICA) served as the standard of reference, using a quantitative approach.

Methods CTA studies were performed using CT equipment with 320 detector-rows, each $0.5 \mathrm{~mm}$ wide, and a gantry rotation time of $0.35 \mathrm{~s}$. All grafts, recipient and nongrafted vessels were deemed interpretable or uninterpretable. The presence of significant $(\geq 50 \%)$ stenosis and occlusion were determined on vessel and patient basis. Results were compared to ICA using quantitative coronary angiography. Results A total of 40 patients ( 28 men, $76 \pm 15$ years), with 89 grafts, were included in the study. On a graft analysis,
\end{abstract}

F. R. de Graaf $(\bowtie) \cdot$ J. E. van Velzen · A. J. Witkowska •

J. D. Schuijf · J. J. Bax • G. J. de Grooth $\cdot$ J. W. Jukema

E. E. van der Wall

Department of Cardiology, Leiden University Medical Center,

Albinusdreef 2 Postal zone: C5-P, P.O. Box 9600, 2300 RC

Leiden, The Netherlands

e-mail: f.r.de_graaf@lumc.nl

J. E. van Velzen · J. W. Jukema • E. E. van der Wall

The Interuniversity Cardiology Institute of the Netherlands,

Utrecht, The Netherlands

N. van der Bijl • L. J. Kroft • A. de Roos

Department of Radiology, Leiden University Medical Center,

Leiden, The Netherlands

J. H. C. Reiber

Division of Image Processing, Department of Radiology,

Leiden University Medical Center,

Leiden, The Netherlands the sensitivity, specificity, positive and negative predictive values in the evaluation of significant stenosis were $96 \%$, $92 \%, 83 \%$ and $98 \%$ respectively. The diagnostic accuracy for the assessment of recipient and nongrafted vessels was $89 \%$ and $80 \%$, respectively. The diagnostic accuracy for the assessment of graft, recipient and nongrafted vessel occlusion was $96 \%, 92 \%$ and $100 \%$, respectively.

Conclusions 320-slice CTA allows accurate non-invasive assessment of significant graft, recipient vessel and nongrafted vessel stenosis in patients with prior CABG.

Keywords Multidetector computed tomography

Non-invasive coronary angiography - Coronary artery bypass grafts · Cardiac imaging · Cardiac-gated imaging techniques

$\begin{array}{ll}\text { Abbreviations } \\ \text { CABG } & \text { coronary artery bypass grafting } \\ \text { CAD } & \text { coronary artery disease } \\ \text { CI } & \text { confidence interval } \\ \text { CTA } & \text { computed tomography coronary angiography } \\ \text { ICA } & \text { invasive coronary angiography } \\ \text { LAD } & \text { left anterior descending coronary artery } \\ \text { LCx } & \text { left circumflex coronary artery } \\ \text { NPV } & \text { negative predictive value } \\ \text { PCI } & \text { percutaneous coronary intervention } \\ \text { PPV } & \text { positive predictive value } \\ \text { RCA } & \text { right coronary artery }\end{array}$

\section{Introduction}

Coronary artery bypass grafting $(\mathrm{CABG})$ is frequently performed in order to restore myocardial perfusion in 
patients with severe three-vessel disease or left main coronary artery stenosis [1]. At present, invasive coronary angiography (ICA) is the standard of reference for the detection of stenotic coronary artery disease (CAD) in patients with prior CABG. However, ICA is associated with a small but non-negligible risk of complications, patient discomfort, and costs of hospital stay [2]. As a result, a non-invasive investigation to assess patients after $\mathrm{CABG}$ may be of clinical benefit in selected patients.

Over the past decade multidetector computed tomography coronary angiography (CTA) has become an important imaging modality for the non-invasive assessment of CAD [3-6]. This technique enables the non-invasive visualization of cardiac anatomy, coronary arteries, stents and grafts with good spatial resolution [7-9]. The diagnostic performance of CTA for the evaluation of patients with prior CABG has increased with each new generation of CT equipment [10]. Using older generations such as 16-slice CTA, high diagnostic accuracy was reported in the assessment of graft patency and significant stenosis [1113], while the assessment of significant stenosis in native coronary arteries remained suboptimal [14-16]. Using 64slice CTA, the efficacy of CTA in the detection of significant stenosis in native coronary arteries and grafts improved, with fair diagnostic accuracy in the detection of graft and native vessel stenosis, but still at the cost of high radiation and contrast doses $[17,18]$.

Recently, 320-slice CT systems were introduced, with a maximum of $16 \mathrm{~cm}$ volumetric coverage in a single gantry rotation. With the simultaneous acquisition of 320 slices per rotation, a volumetric $\mathrm{CT}$ data acquisition approach is used, thereby reducing radiation burden, time of breath-hold and contrast load [19]. Good diagnostic performance of 320-slice CTA has been previously demonstrated in the assessment of CAD [20-22]. The assessment of patients with prior CABG, however, has not been formerly reported. The purpose of the present study, therefore, was to assess the diagnostic performance of 320 -slice CTA in patients with previous $\mathrm{CABG}$, in the evaluation of significant stenosis and occlusion in grafts, recipient vessels and nongrafted vessels.

\section{Materials and methods}

Patient population

The patient population consisted of 40 consecutive patients with a history of CABG (mean 16.3 years). A total of 35 patients were scheduled for both CTA and ICA for visualization of coronary anatomy and cardiac structures $[23,24]$. Specifically, 32 patients were referred for CTA for preprocedural evaluation prior to transcatheter aortic valve implantation $[23,25]$ and 3 patients undergoing catheter ablation for atrial fibrillation were referred for CTA [24, 26]. In addition, 5 patients were referred for ICA following CTA based on CTA findings and clinical presentation. All patients were symptomatic. In total, 34 patients presented with angina pectoris, and in 17 patients dyspnoea was present. This evaluation was conducted according to the clinical protocol of the institution. All patients provided informed consent for the procedures. Patients were entered prospectively into the departmental Cardiology Information System (EPD-Vision ${ }^{\circledR}$, Leiden University Medical Center) and were retrospectively analysed. Table 1 shows an overview of the baseline clinical characteristics of the patient population. Exclusion criteria for CTA investigation were: (supra) ventricular arrhythmias, known allergy to iodine contrast material, renal failure (glomerular filtration rate $<30 \mathrm{ml} / \mathrm{min}$ ), severe claustrophobia, pregnancy and high heart rate in the presence of contraindications to beta-blocking medication. ICA served as the standard of reference. Both examinations were performed within 3 months of each other. No interventions or changes in the clinical condition of the patients occurred between the examinations.

CTA data acquisition

CTA investigations were performed using 320-row multidetector CT (Aquilion ONE, Toshiba Medical Systems,

Table 1 Patient characteristics $(n=40)$

\begin{tabular}{ll}
\hline Men/women & $28 / 12$ \\
Age (years) & $76 \pm 15$ \\
Time after CABG (years) & $16.3 \pm 7.6$ \\
BMI $\left(\mathrm{kg} / \mathrm{m}^{2}\right)$ & $25 \pm 3$ \\
Family history of CAD $^{\mathrm{a}}$ & $9(23 \%)$ \\
Diabetes $^{\text {Hypertension }}{ }^{\mathrm{b}}$ & $11(28 \%)$ \\
Hypercholesterolemia $^{\mathrm{c}}$ & $35(88 \%)$ \\
Current smoker $^{\text {Previous myocardial infarction }}$ & $30(75 \%)$ \\
Previous PCI $_{\text {Pacemaker or ICD }}$ & $3(8 \%)$ \\
\hline
\end{tabular}

Values in parentheses are percentages

${ }^{a}$ Defined as presence of coronary artery disease in first degree family members at $<55$ years in men and $<65$ years in women

${ }^{\mathrm{b}}$ Defined as systolic blood pressure $\geq 140 \mathrm{~mm} \mathrm{Hg}$ and/or diastolic blood pressure $\geq 90 \mathrm{~mm} \mathrm{Hg}$ and/or the use of antihypertensive medication

${ }^{\mathrm{c}}$ Serum total cholesterol $\geq 230 \mathrm{mg} / \mathrm{dl}$ and/or serum triglycerides $\geq 200 \mathrm{mg} / \mathrm{dl}$ or treatment with lipid lowering drugs

$B M I$ Body Mass Index. $C A B G$ coronary artery bypass grafting. $C A D$ : coronary artery disease. $I C D$ Implantable cardiac defibrillator. $P C I$ percutaneous coronary intervention 
Otawara, Japan) with 320 detector rows each $0.5 \mathrm{~mm}$ wide and a gantry rotation time of $0.35 \mathrm{~s}$. If the patient's heart rate exceeded 65 beats $/ \mathrm{min}$, oral beta-blocking medication (50 or $100 \mathrm{mg}$ metoprolol) was administered $1 \mathrm{~h}$ before examination, unless contraindicated. In addition, sublingual nitroglycerin ( 0.4 or $0.8 \mathrm{mg}$ ) was administered $5 \mathrm{~min}$ before the CTA investigation, if tolerated. A tri-phasic protocol for the administration intravenous contrast medium was used. The total amount of non-ionic contrast agent (Iomeron 400; Bracco, Milan, Italy) injected into the antecubital vein was 60-80 $\mathrm{ml}$ (depending on body weight). Patients examined using the venous graft protocol (in the presence of only venous grafts, $n=14$ ) received $50-70 \mathrm{ml}$ of contrast media at a flow rate of 5.0 or $6.0 \mathrm{ml} / \mathrm{s}$, followed by $20 \mathrm{ml}$ of $50 \%$ contrast/saline. Patients examined using an arterial graft protocol (in the presence of at least one arterial graft, $n=26$ ) received $60-80 \mathrm{ml}$ of contrast media at a flow rate of 5.0 or $6.0 \mathrm{ml} / \mathrm{s}$, followed by $30 \mathrm{ml}$ of $50 \%$ contrast/saline. Subsequently, a saline flush of 25-30 ml was administered at a flow rate of $3.0 \mathrm{ml} / \mathrm{s}$. An automated peak enhancement detection technique was used to determine arrival of contrast agent in the left ventricle (LV) to synchronize the arrival of the contrast media and the CT data acquisition, using a threshold of +180 Hounsfield Units.

CTA images were acquired during an inspiratory breathhold of approximately $5 \mathrm{~s}$. During the CT data acquisition, the ECG was registered simultaneously for prospective triggering of the data. The phase window was set at $30-80 \%$ of the R-R interval in patients with a stable heart rate $\leq 65$ beats $/ \mathrm{min}$. In patients with a heart rate $>65$ beats $/ \mathrm{min}$, CTA acquisition was performed during multiple heart beats (typically two). In patients requiring LV function measurements, image acquisition was performed during an entire R-R interval using tube current modulation. Tube voltage and current were adapted to body mass index (BMI) and thoracic anatomy as described [20]. Tube voltage ranged from $100-135 \mathrm{kV}$ and maximal tube current was 400-580 mA.

In both venous and arterial graft protocols, the heart and ascending aorta were examined in a single volume with a cranio-caudal anatomical range of $16 \mathrm{~cm}$. Additionally, in patients examined using an arterial graft protocol, a second, untriggered volume was acquired, with the upper limit set at the proximal origin of the (internal mammary) arterial graft from the subclavian artery and the lower limit equal to the upper limit of the triggered volume.

An initial data set was reconstructed at $75 \%$ of $\mathrm{R}-\mathrm{R}$ interval. A slice thickness of $0.50 \mathrm{~mm}$ was obtained and the reconstruction interval was set to $0.25 \mathrm{~mm}$. If multiple phases were obtained, the cardiac phase with the least motion artifacts was used [7]. For processing and assessment, images were transferred to a remote workstation with dedicated CTA analysis software (Vitrea FX 1.0, Vital Images, Minnetonka, MN, USA). During the CTA exami- nation the average heart rate was $62 \pm 14$ beats/min (range 44-99 beats/min).

Radiation dose was quantified with a dose-length product conversion factor of $0.014 \mathrm{mSv} /(\mathrm{mGy} \times \mathrm{cm})$ as described [27]. In patients in whom the heart was examined in a single cardiac cycle, estimated mean radiation doses were $7.8 \pm 3.3 \mathrm{mSv}$ when $\mathrm{LV}$ function measurements were not performed and $11.2 \pm 4.1 \mathrm{mSv}$ when $\mathrm{LV}$ function measurements were performed.

\section{CTA data analysis}

CTA image analysis was performed by 2 observers in consensus, experienced in the evaluation of CTA and blinded to the results of ICA. Firstly, three-dimensional volume rendered reconstructions were used to obtain general information regarding the status and anatomy of the grafts and coronary arteries. Subsequently, axial slices were visually examined for the presence of significant narrowing by determining the presence of $\geq 50 \%$ reduction of luminal diameter and vessel occlusion [28]. The analysis was assisted by curved multiplanar reconstructions of all vessels. Data were analyzed on a vessel and patient basis. All vessels were evaluated, including those $<1.5 \mathrm{~mm}$ in diameter. In the evaluation of a bypass graft, the distal anastomosis was regarded as part of the graft.

The recipient vessel sections distal to the graft anastomosis were regarded as separate vessels. Sections proximal to the graft anastomosis were not evaluated. However, in case a graft was occluded, patency of coronary vessel sections proximal to the site of anastomosis of the graft was also evaluated (owing to the therapeutic importance with regard to eligibility for revascularization). Of nongrafted vessels, the left anterior descending coronary artery (LAD), left circumflex coronary artery ( $\mathrm{LCx}$ ) and the right coronary artery (RCA) were assessed as separate vessels. The left main and diagonal vessels were considered to be part of the LAD. The intermediate branch and obtuse marginal branch were considered part of the LCx.

All grafts, recipient vessels and nongrafted vessels were deemed interpretable or uninterpretable. Subsequently, interpretable grafts, recipient vessels and nongrafted vessels were evaluated for the presence of significant stenosis and occlusion. Finally, patient-based analysis was performed. In case one vessel was uninterpretable, an intention to diagnose strategy was applied. However, if more than one vessel was uninterpretable, the entire examination was considered to be of non-diagnostic image quality. Subsequently, CTA investigations were evaluated for the presence of significant stenosis and occlusion. Uninterpretable grafts, recipient vessels and nongrafted vessels as well as non-diagnostic examinations were included in the analysis and considered positive for the presence of significant stenosis or occlusion. 
Quantitative coronary angiography

ICA was performed according to a standard procedure using a femoral approach. Angiograms were assessed by an independent experienced observer blinded to CTA data. All grafs, recipient vessels and nongrafted vessels were visually classified as normal (no atherosclerosis or minor wall irregularities with $\leq 20 \%$ luminal narrowing) or abnormal ( $>20 \%$ luminal narrowing). To objectively determine stenosis severity, all vessels visually scored as abnormal were quantified using a dedicated and validated quantitative coronary angiography software package (QAngioXA 6.0, CA-CMS, Medis Medical Imaging Systems, Leiden, The Netherlands). Quantitative coronary angiography was performed according to standardized methods [29, 30]. All vessels were evaluated for the presence of significant $(\geq 50 \%)$ stenosis in the angiographic view with most severe luminal narrowing. Figure 1 shows an example of a significant stenosis in a venous graft on CTA and confirmed on quantitative coronary angiography.

\section{Statistical analysis}

CTA data were compared to ICA analyses. Data were analyzed on a vessel and patient basis. Sensitivity, specificity and positive and negative predictive values, including 95\% confidence intervals (CI), for the detection of significant stenosis and occlusion on ICA were calculated for all vessels. Continuous data were expressed as mean \pm
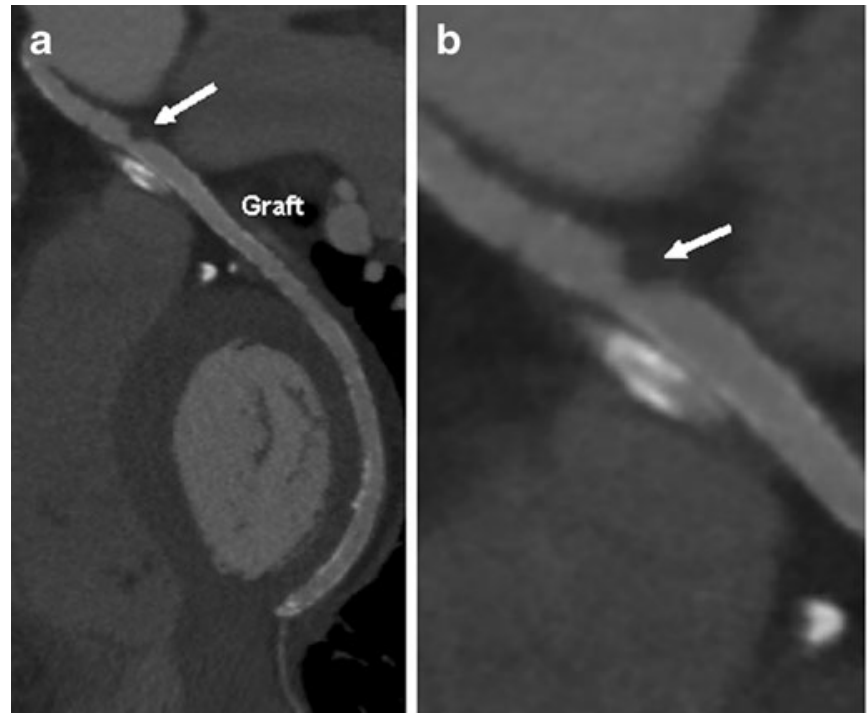

Fig. 1 An example of a significant stenosis in a venous graft visualized using 320-slice CTA and confirmed on quantitative coronary angiography. A significant lesion in the proximal venous graft supplying the OM and PLCx was identified on CTA. A) Curved multiplanar reconstruction depicting a severe lesion in the proximal graft (arrow). B) Enlarged curved multiplanar reconstruction of the proximal graft and lesion (arrow) showing significant luminal
SD. A value of $p<0.05$ was considered statistically significant and all reported p-values were two-sided. Statistical analyses were performed using SPSS software version 16 (SPSS, Inc., Chicago, Illinois).

\section{Results}

Patient population

A total of 40 patients were eligible for CTA and were included in the study. The clinical baseline characteristics of the patient population are shown in Table 1. CTA examinations were successfully completed in 38 patients. One CTA examination was of non-diagnostic image quality due image degradation related to motion artifacts in a patient with a heart rate of 93 beats/min during image acquisition. A second CTA examination was rendered nondiagnostic due to image noise. As a result, 38 patients with a mean of $2.3 \pm 1.0$ grafts (range 1-6) and a mean of $3.4 \pm$ 1.5 anastomoses (range 1-8) were available for vesselbased analysis. A total of 89 grafts were available for evaluation ( 28 arterial grafts and 61 venous grafts). Graft characteristics are summarized in Table 2.

\section{Detection of significant graft and coronary stenosis}

On ICA, 89 grafts were available for evaluation. A total of 26 grafts had a significant stenosis on ICA. Two grafts
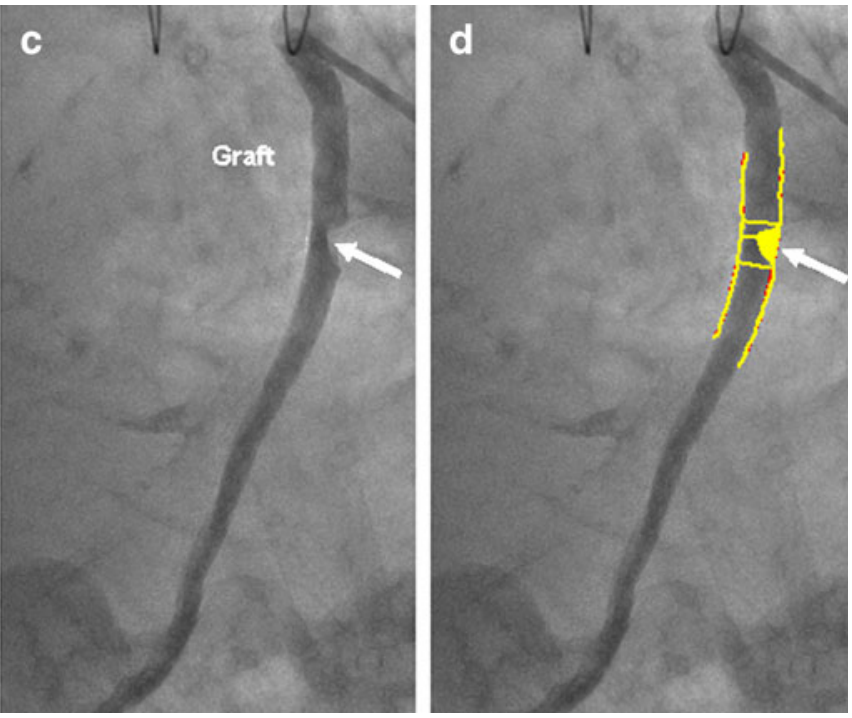

narrowing. C) The findings were confirmed on ICA. D) Quantitative coronary angiography analysis demonstrating 55\% luminal narrowing (arrow). Abbreviations: CTA: computed tomography coronary angiography. ICA: invasive coronary angiography. OM: obtuse marginal branch. PLCx: posterolateral branch of the left circumflex coronary artery 
Table 2 Graft characteristics

\begin{tabular}{lc}
\hline Total number of grafts & 89 \\
Single arterial grafts & $18(20 \%)$ \\
Sequential arterial grafts & $10(11 \%)$ \\
Single venous grafts & $38(43 \%)$ \\
Sequential venous grafts & $23(26 \%)$ \\
Total number of nongrafted vessels & 26 \\
LAD & $4(15 \%)$ \\
LCx & $6(23 \%)$ \\
RCA & $16(62 \%)$ \\
Total number of anastomosis & 129 \\
LAD $^{\text {a }}$ & $60(46 \%)$ \\
LCx $^{\text {a }}$ & $45(35 \%)$ \\
RCA $^{\text {a }}$ & $24(19 \%)$ \\
\hline
\end{tabular}

${ }^{\mathrm{a}}$ Denotes vessel territory

Values in parentheses are percentages

$L A D$ left anterior descending coronary artery. $L C x$ left circumflex coronary artery. $R C A$ right coronary artery

(2.2\%) were of non-diagnostic image quality on CTA and considered positive for the presence of significant stenosis. Both grafts were arterial grafts which were rendered nondiagnostic due to clip-artifacts. CTA accurately detected 25 grafts with significant stenosis. However, in 5 grafts stenosis severity was overestimated whereas 1 graft was incorrectly identified as having non-significant stenosis. Table 3 shows the diagnostic accuracy of 320-slice CTA in the detection of significant graft stenosis. Figures 2 and 3 show examples of 320-slice CTA investigations of patients with a patent venous and arterial graft, respectively.

A total of 127 recipient vessels were available for evaluation as 2 recipient vessels of obstructed grafts were not visualized on ICA. Nine recipient vessels (7.1\%) were of non-diagnostic image quality on CTA and considered positive. CTA correctly identified 22 significant recipient vessel stenoses. A total of 3 significant recipient vessel stenoses were underestimated by CTA while 11 recipient vessels were incorrectly deemed significant. Table 3 shows the diagnostic accuracy of 320-slice CTA in the detection of significant recipient vessel stenosis.

On ICA, 25 nongrafted vessels were assessed, with a total of 12 significant stenoses. One nongrafted vessel was not available on ICA. On CTA, one nongrafted vessel $(4.0 \%)$ was of non-diagnostic image quality and considered positive. Ten significant nongrafted vessel stenoses were accurately detected by CTA. However, 2 nongrafted vessels were incorrectly deemed non-significant while the degree of stenosis in 3 nongrafted vessels was overestimated. Table 3 shows an overview of the diagnostic accuracy of 320-slice CTA in the detection of significant nongrafted vessel stenosis.

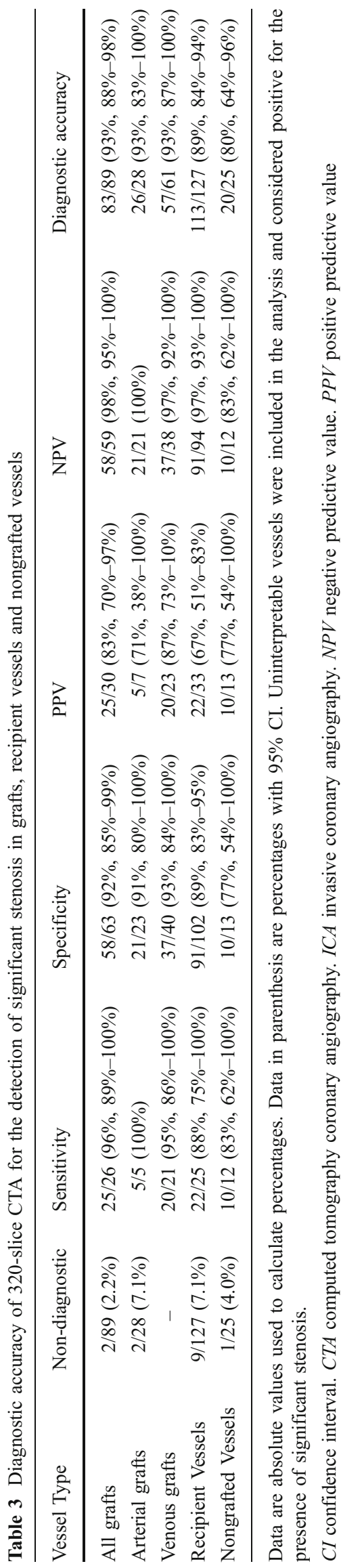



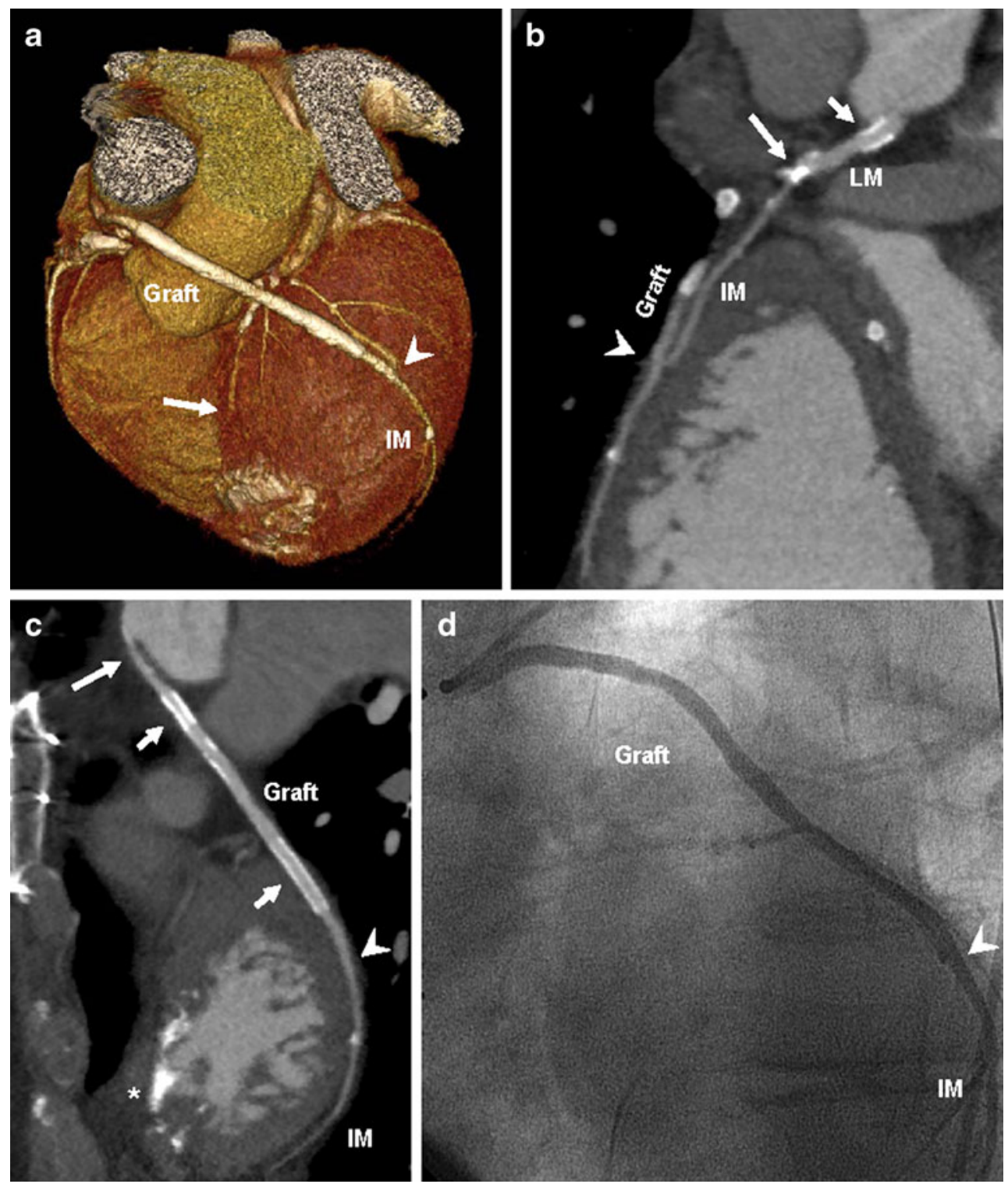

Fig. 2 Example of 320-slice CTA of a 75 year-old man with a history of $\mathrm{CABG}$ and PCI. Panel A shows a three-dimensional volume rendered reconstruction of the heart. A single venous graft is shown with an anastomosis on the IM (arrowhead). The LAD is functionally occluded (arrow). Panel B shows a curved multiplanar reconstruction, revealing a diseased native IM, with a severely calcified lesion at the origin (long arrow) and small vessel caliber. Furthermore, a patent stent in the LM is observed. In panel $\mathrm{C}$, a curved multiplanar reconstruction of the venous graft is shown revealing proximal luminal narrowing (long arrow). Two patent stents are identified in the venous graft (short arrows), without the presence of in-stent restenosis. Additionally, a patent anastomosis with the IM is shown (arrowhead) with good distal runoff and a non-significant calcified lesion. In addition, signs of an old myocardial infarction are observed, with calcifications in the anteroseptal, anterior apical and midventricular myocardium $(*)$. Graft and anastomosis (arrowhead) patency as well as good distal runoff in the IM were confirmed on ICA (panel D). Abbreviations: CABG: coronary artery bypass grafting. CTA: computed tomography coronary angiography. ICA: invasive coronary angiography. IM: intermediate branch. LAD: left anterior descending coronary artery. LM: left main artery. PCI: percutaneous coronary intervention

\section{Detection of graft and coronary occlusion}

Of 89 grafts available on ICA, 23 grafts $(25.8 \%)$ were occluded. CTA accurately identified all graft occlusions while 4 grafts were incorrectly deemed occluded. Table 4 shows an overview of the diagnostic accuracy of 320-slice
CTA in the detection of grafts occlusion. Figure 4 shows an example of an occluded venous graft visualized using 320slice CTA.

In 127 recipient vessels eligible for evaluation, 11 occluded vessels were identified on ICA. CTA correctly identified all occluded recipient vessels while a total of 10 

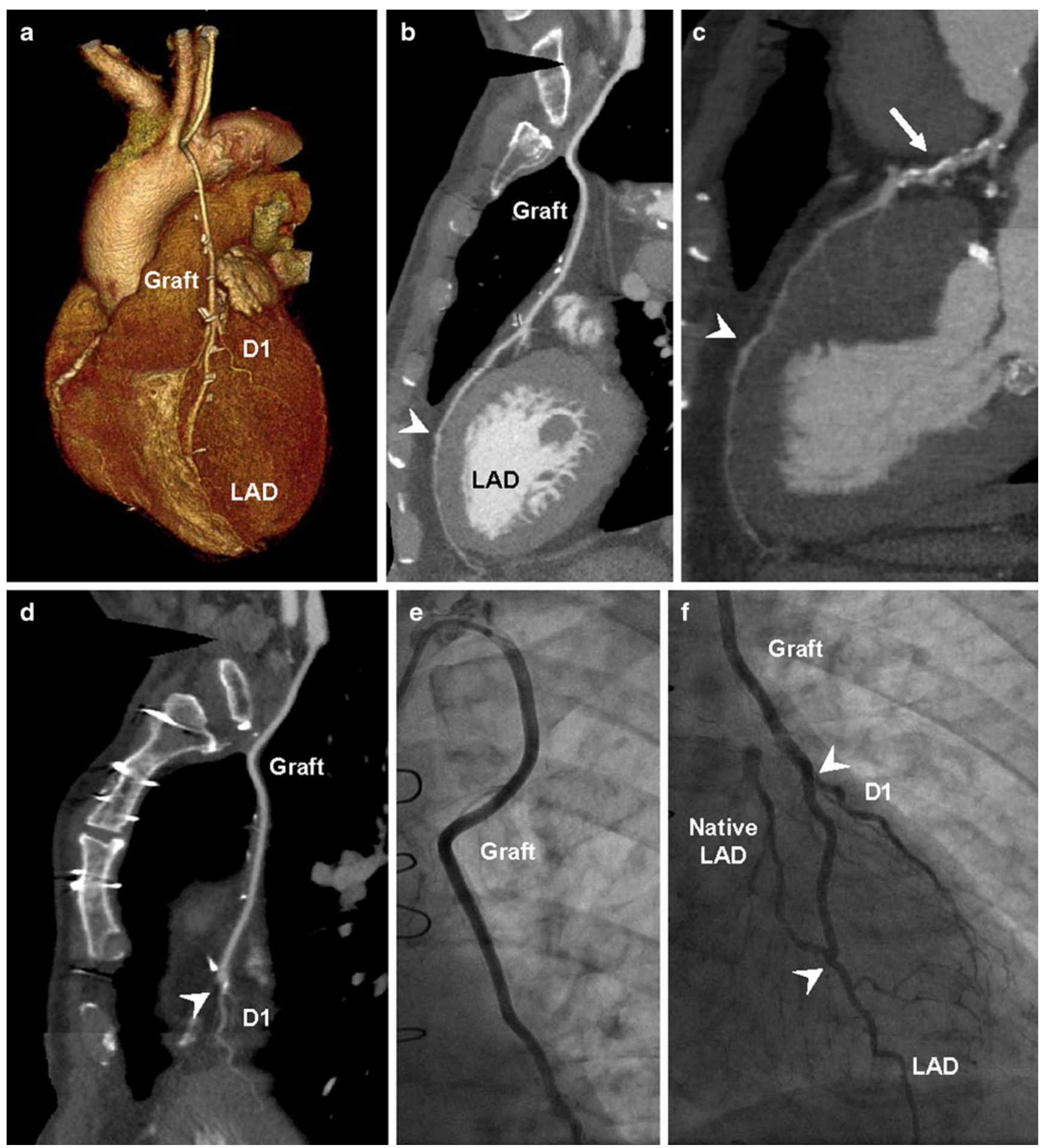

Fig. 3 Example of 320-slice CTA of an arterial graft in a 74 year-old man who underwent CABG 7 years ago. Panel A shows a threedimensional volume rendered reconstruction of the heart, and bypass trajectory. An arterial graft is visible, with anastomoses to the D1 and LAD. Panel B shows the curved multiplanar reconstruction of a patent graft without the presence of significant graft stenosis. A patent anastomosis is observed (arrowhead) with good runoff in the distal LAD. In Panel $\mathrm{C}$, the curved multiplanar reconstruction of a heavily diseased LAD is shown, with severe stenosis of the proximal LAD

(arrow). In Panel D, a curved multiplanar reconstruction of the arterial graft and D1 are shown. The anastomosis of the graft to the patent D1 is uninterpretable due to a dense calcification. In Panel $\mathrm{E}$ and $\mathrm{F}$ the concordant ICA examinations are shown, confirming graft and vessel patency. Abbreviations: CABG: coronary artery bypass grafting. CTA: computed tomography coronary angiography. D1: first diagonal branch. ICA: invasive coronary angiography. LAD: left anterior descending coronary artery 
vessels were inaccurately judged to be occluded. The diagnostic accuracy for the detection of recipient vessel occlusion is shown in Table 4.

On ICA, 25 nongrafted vessels were assessed, with a total of 6 nongrafted vessel occlusions. No nongrafted vessel occlusions were missed or incorrectly identified on CTA. Table 4 shows an overview of the diagnostic accuracy of 320-slice CTA in the detection of nongrafted vessel occlusion.

Patient-based analysis

A total of 40 patients were available for analysis on ICA. However, in 2 patients (5.0\%) CT was of of non-diagnostic image quality, and considered positive for the presence of significant stenosis. A total of 32 patients with a significant graft or coronary stenosis were identified on ICA. On CTA, 3 patients were incorrectly diagnosed with significant stenosis. In 1 patient, the recipient LAD of a sequential arterial graft was incorrectly judged obstructed. In a second patient, the anastomosis of a sequential venous graft to the first diagonal branch was inaccurately deemed occluded. In a third patient, the examination was of non-diagnostic quality and therefore considered positive for the presence of significant stenosis. Of the remaining patients, CTA correctly excluded the presence of significant stenosis in 5 patients, while 30 patients were accurately diagnosed with significant graft, recipient vessel or nongrafted vessel stenosis. Accordingly, on a patient basis, the sensitivity, specificity, positive and negative predictive values were $94 \%, 62 \%, 91 \%$ and $71 \%$, respectively. As a result, the diagnostic accuracy was $88 \%$.

\section{Discussion}

The present investigation demonstrated good diagnostic accuracy of 320-slice CTA in the evaluation of significant graft, recipient and nongrafted vessel stenosis and occlusion in patients with prior $\mathrm{CABG}$.

Detection of graft and native vessel stenosis

The current findings showed high diagnostic accuracy in the detection of significant graft stenosis and occlusion using 320-slice CTA. Importantly, only $2 \%$ of grafts were uninterpretable. Diagnostic accuracy in the detection native vessel stenosis was slightly lower as compared to the evaluation of grafts, mainly due to lower positive predictive values.

The current results compare favorably with prior data obtained with previous generations, including 64-slice CTA. Although the diagnostic performance for 320-slice 

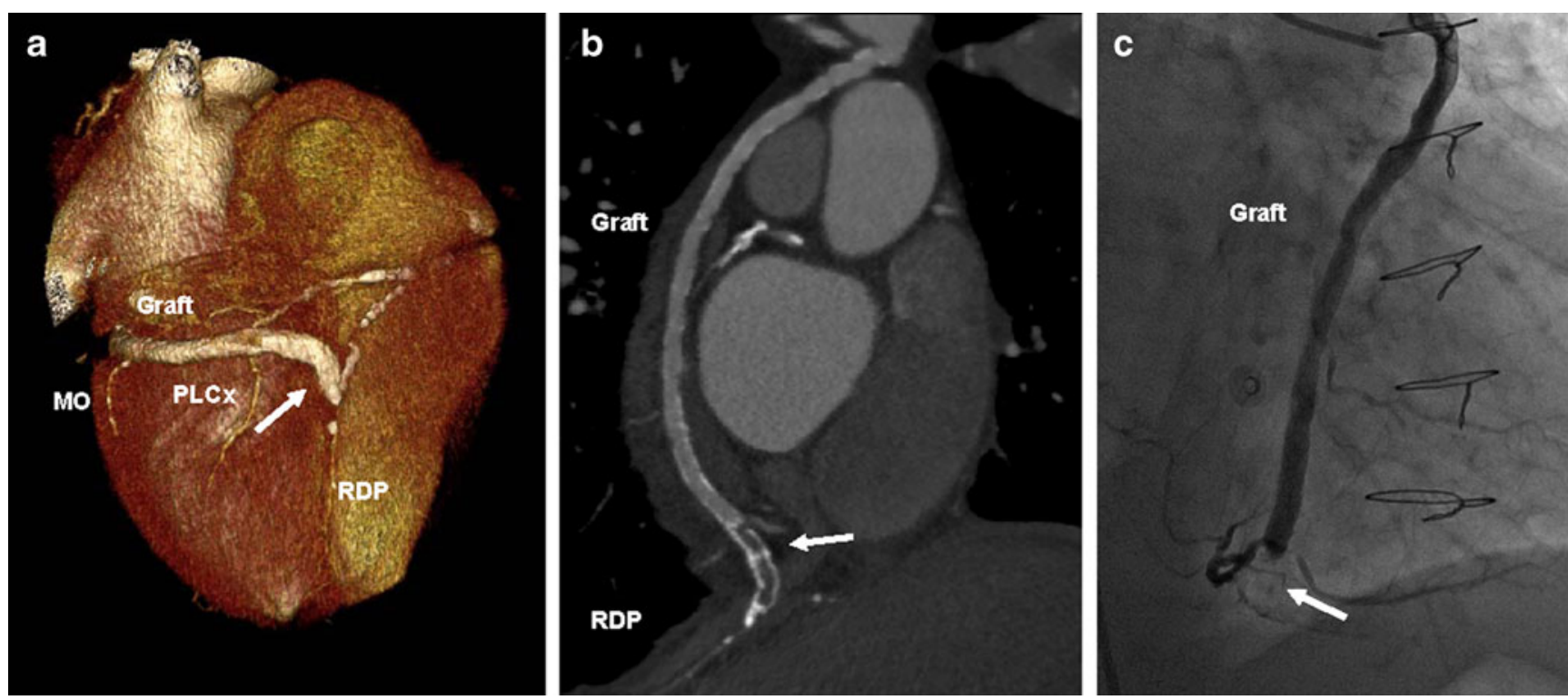

Fig. 4 Example of 320-slice CTA of an occluded venous graft in a 79 year-old man who underwent CABG 25 years ago. Panel A shows a three-dimensional volume rendered reconstruction of the heart. A venous graft is shown, with anastomoses to the MO, PLCx and PDA. Two stents are present in the distal graft (arrow). Panel B shows a curved multiplanar reconstruction indicating the presence of a graft occlusion in the stented distal graft, immediately before the anasto-

CTA was not higher than that reported by prior diagnostic accuracy studies for 64-slice CTA[31], in the present analysis non-diagnostic vessels and scans were included. In addition all segments (including mall segments $(<1.5 \mathrm{~mm}))$ were included in the analysis. In many other prior diagnostic accuracy studies segments $<1.5 \mathrm{~mm}$ as well as non-diagnostic vessels were excluded from the analysis, thereby increasing the reported diagnostic accuracy. Nevertheless, although graft evaluation was good, also in the current study the assessment of native vessels remained challenging [32, 33]. To a large extent, this observed difference in diagnostic performance may be attributed to the fact that patients with prior CABG are generally older with longstanding $\mathrm{CAD}$ and thus more advanced and calcified CAD in both distal runoff and native coronary arteries [18, 32, 34]. Indeed, Ropers et al., assessing 50 patients with a total of 138 grafts using 64-row CTA, reported that the diagnostic accuracy in the assessment of recipient and nongrafted vessels was considerably lower ( $85 \%$ and $73 \%$ respectively) as compared to the performance in grafts $(96 \%)$ on a per segment basis [32]. Although diagnostic accuracy in the evaluation of grafts was good, $9 \%$ of nongrafted vessels were nondiagnostic, even while small segments $(<1.5 \mathrm{~mm})$ were excluded from analysis [32]. Moreover, in a study by Malagutti et al. performing 64-row CTA in 52 symptomatic patients with a total of 109 grafts, while the performance of CTA for graft mosis to the RDP. The graft occlusion was confirmed on ICA (arrow, Panel C). Abbreviations: CABG: coronary artery bypass grafting. CTA: computed tomography coronary angiography. ICA: invasive coronary angiography. OM: obtuse marginal branch. PDA: posterior descending coronary artery. PLCx: posterolateral branch of the left circumflex coronary artery

assessment was good ( $98 \%$ on a patient basis), nongrafted coronary stenosis was overestimated in 8 out of 19 patients without significant CAD yielding a low positive predictive value of $42 \%$ [33]. The current study showed superior results, especially taking into account that small and uninterpretable vessels were included in the analysis. Consistent with what has been previously reported however $[20,21]$, the diagnostic performance of 320-slice CTA for the detection of significant stenosis in native coronary arteries in patients with prior $\mathrm{CABG}$ remained lower than in patients without prior CABG [20, 22].

Slightly higher diagnostic accuracy for the evaluation of grafts and native vessels has been reported with other novel CTA technologies. Weustink et al., using dual-source CTA in 52 patients with prior $\mathrm{CABG}$, reported excellent diagnostic accuracy in the evaluation of patients with a history of CABG, with a diagnostic accuracy of $100 \%$ in the evaluation of graft stenosis on a segment basis [35]. The high diagnostic accuracy may be partly contributed to the superior temporal resolution of dual-source CTA. Importantly, it is further explained by the fact that average patient age was 10 years younger than the present population and average duration of graft implantation was shorter ( 9.6 years vs 16.3 years in the present study). Considering the fact that older patients with longstanding graft implantation tend to have more advanced CAD and heavy calcifications, it is conceivable that the impact of these patient characteristics 
on image quality and diagnostic performance of CTA may have been substantial. Furthermore, small segments $(<1.5 \mathrm{~mm})$ and non-diagnostic segments $(2 \%)$ were excluded from analysis in the study by Weustink et al., while these were included in the present investigation.

\section{Volumetric 320-slice CTA}

Volumetric imaging offers several advantages as compared to helical or step-and-shoot techniques. First, volumetric data acquisition reduces patient radiation burden, as it eliminates helical oversampling [21, 36, 37]. At present, owing to novel technology, radiation exposure for CTA in the general population referred for CTA may be equivalent to or lower than diagnostic ICA [38]. Preliminary results showed that radiation dose below $5 \mathrm{mSv}$ can be achieved in patient without known CAD, using 320-slice CTA with a heart rate below 65 beats/min [20,39]. However, in patients with prior $\mathrm{CABG}$, CTA radiation exposure is generally higher than in patients evaluated for the exclusion of CAD [20], since the enlarged anatomical range covers the entire bypass trajectory. Novel developments in 320-slice CTA protocols or other technologies, such as high-pitch spiral CTA may indeed further reduce radiation exposure [40, 41]. A second advantage of volumetric imaging using 320 -slice CTA is that the contrast load is reduced, due to a small data acquisition window, which is a particular advantage to patients with prior $\mathrm{CABG}$, in whom reduced renal function is prevalent [42]. Furthermore, the short time of breath-hold reduces the problem of respiratory motion artifacts, which is of particularly benefit in patients of more advanced age (such as CABG patients) who may be unable to perform extended breath-holds.

\section{Clinical implications}

Although ICA remains the gold standard for the evaluation of patients with prior $\mathrm{CABG}$, in patients in whom only graft visualization is required (for instance following failed invasive imaging or equivocal functional test results) CTA may omit the need for (repeat) ICA. CTA may furthermore be a useful alternative in patients in whom ICA is preferably avoided due to a higher risk of procedural complications. In addition, in patients with a history of CABG, CTA may aid planning of subsequent percutaneous coronary intervention by providing detailed anatomical information, thereby shortening the time of procedure, contrast load and radiation burden [43]. CTA may also be useful for presurgical evaluation in patients undergoing reoperative cardiac surgery [44]. Moreover, CTA enables the rapid and comprehensive representation of complex graft anatomy and could thus be used in patients with an incomplete surgical history, in whom precise graft anatomy is unknown. Accordingly, in clinical practice CTA may be used as a noninvasive alternative to ICA in carefully selected patients. The precise role of CTA in clinical practice for the assessment of patients with a history of CABG merits further investigation.

\section{Limitations}

Several limitations of the present study merit further consideration. First, CTA is inherently associated with radiation exposure [45]. Still, radiation dose reported in the present study was relatively high as compared to other 320-slice CT studies in which patients without prior CABG were evaluated [20]. Optimizing scan protocols for individual patients is relevant. In the present study, a relatively large (30-80\%) RR interval was used for image acquisition to optimize image quality. Patients with bypasses typically have heavily diseased native coronary arteries [34]. Good image quality is especially needed for evaluation of these poor quality native arteries, as well as for evaluating distal bypass anastomoses, which are small structures. Moreover, the extra rotation up to the subclavian arteries in patients with arterial bypasses increased radiation dose.

Although 320-slice CTA is associated with patient radiation and contrast exposure, referral for ICA may expose patients to even higher doses of radiation and contrast material, particularly in the case of patients with prior $\mathrm{CABG}$. Although comparison in patients with prior CABG is lacking, CTA radiation doses equal or lower than that of diagnostic ICA have been reported in the general population referred for ICA $[38,46]$. Second, in certain cases, results of CTA investigation may have resulted in patient referral for ICA. Third, the present study group was not a randomly selected patient cohort. While the direct study of randomly selected patients with a history of CABG is currently not feasible due to lack of indication for CTA, the present investigation represents an adequate pilot study. Furthermore, the present investigation is limited by a small study population and additional investigations in larger patient cohort and preferably in a multi-center setting are preferred. Last, an important limitation of CTA remains the evaluation native vessels due to decreased performance in the presence of dense calcified plaque or small coronary branches.

\section{Conclusion}

The present investigation demonstrated a good diagnostic accuracy of 320-slice CTA for the non-invasive evaluation of venous and arterial grafts. In addition, recipient vessels and nongrafted vessels may be evaluated with fair diagnostic accuracy, although the assessment of small 
coronary branches and heavily calcified vessels remains challenging. Nevertheless, in selected cases, CTA my potentially aid the work up of patients with prior CABG.

Acknowledgements Dr. de Graaf is co-supported by the Dutch Technology Foundation STW (Utrecht, the Netherlands), applied science division of NWO and the Technology Program of the Ministry of Economic Affairs, grant nr. 10084. Dr. van Velzen is supported by the Netherlands Heart Foundation (The Hague, The Netherlands), grant nr 2007B223. Dr. Bax has research grants from Medtronic (Minneapolis, United States), Boston Scientific (Natick, United States), BMS medical imaging (New York, United States), St. Jude Medical (St. Paul, United States), GE Healthcare (Chalfont St Giles, United Kingdom), Biotronik (Berlin, Germany), and Edwards Lifesciences (Irvine, United States). Dr. Jukema has research grants from and was speaker on (CME accredited) meetings sponsored by Astellas (Tokyo, Japan), Astra-Zeneca (London, United Kingdom), Biotronik (Berlin, Germany), Boston Scientific (Natick, United States), Bristol Myers Squibb (New York, United States), Cordis (Roden, Netherlands), Daiichi Sankyo (Tokyo, Japan), Ely Lilly (Indianapolis, United States), Medtronic (Minneapolis, United States), Merck-Schering-Plough (Whitehouse Station, United States), Pfizer (Groton/New London, United States), Orbus Neich (Hong Kong, China), Novartis (Basel, Switserland), Roche (Basel, Switserland), Servier (Neuilly-sur-Seine, France).

Open Access This article is distributed under the terms of the Creative Commons Attribution Noncommercial License which permits any noncommercial use, distribution, and reproduction in any medium, provided the original author(s) and source are credited.

\section{References}

1. Serruys PW, Morice MC, Kappetein AP, Colombo A, Holmes DR, Mack MJ, Stahle E, Feldman TE, van Den BM, Bass EJ, Van DN, Leadley K, Dawkins KD, Mohr FW (2009) Percutaneous coronary intervention versus coronary-artery bypass grafting for severe coronary artery disease. $\mathrm{N}$ Engl $\mathrm{J}$ Med 360:961-972

2. Elhendy A, van Domburg RT, Bax JJ, Nierop PR, Valkema R, Geleijnse ML, Kasprzak JD, Liqui-Lung AF, Cornel JH, Roelandt JR (1998) Dobutamine-atropine stress myocardial perfusion SPECT imaging in the diagnosis of graft stenosis after coronary artery bypass grafting. J Nucl Cardiol 5:491-497

3. Fernandez GC (2005) Bypass graft imaging and coronary anomalies in MDCT. Eur Radiol 15(Suppl 2):B59-B61

4. Marano R, Liguori C, Rinaldi P, Storto ML, Politi MA, Savino G, Bonomo L (2007) Coronary artery bypass grafts and MDCT imaging: what to know and what to look for. Eur Radiol 17:31663178

5. Budoff MJ, Dowe D, Jollis JG, Gitter M, Sutherland J, Halamert E, Scherer M, Bellinger R, Martin A, Benton R, Delago A, Min JK (2008) Diagnostic performance of 64-multidetector row coronary computed tomographic angiography for evaluation of coronary artery stenosis in individuals without known coronary artery disease: results from the prospective multicenter ACCURACY (Assessment by Coronary Computed Tomographic Angiography of Individuals Undergoing Invasive Coronary Angiography) trial. J Am Coll Cardiol 52:1724-1732

6. Meijboom WB, Meijs MF, Schuijf JD, Cramer MJ, Mollet NR, van Mieghem CA, Nieman K, van Werkhoven JM, Pundziute G, Weustink AC, de Vos AM, Pugliese F, Rensing B, Jukema JW, Bax JJ, Prokop M, Doevendans PA, Hunink MG, Krestin GP, de Feyter PJ (2008) Diagnostic accuracy of 64-slice computed tomography coronary angiography: a prospective, multicenter, multivendor study. J Am Coll Cardiol 52:2135-2144

7. Desbiolles L, Leschka S, Plass A, Scheffel H, Husmann L, Gaemperli O, Garzoli E, Marincek B, Kaufmann PA, Alkadhi H (2007) Evaluation of temporal windows for coronary artery bypass graft imaging with 64-slice CT. Eur Radiol 17:2819-2828

8. de Graaf FR, Schuijf JD (2010) Evaluation of stents and grafts. EuroIntervention 6 Suppl G:G48-G56

9. Andreini D, Pontone G, Bartorelli AL, Trabattoni D, Mushtaq S, Bertella E, Annoni A, Formenti A, Cortinovis S, Montorsi P, Veglia F, Ballerini G, Pepi M (2009) Comparison of feasibility and diagnostic accuracy of 64-slice multidetector computed tomographic coronary angiography versus invasive coronary angiography versus intravascular ultrasound for evaluation of in-stent restenosis. Am J Cardiol 103:1349-1358

10. Stein PD, Beemath A, Skaf E, Kayali F, Janjua M, Alesh I, Olson RE (2005) Usefulness of 4-, 8-, and 16-slice computed tomography for detection of graft occlusion or patency after coronary artery bypass grafting. Am J Cardiol 96:1669-1673

11. Stauder NI, Kuttner A, Schroder S, Drosch T, Beck T, Stauder H, Blumenstock G, Claussen CD, Kopp AF (2006) Coronary artery bypass grafts: assessment of graft patency and native coronary artery lesions using 16-slice MDCT. Eur Radiol 16:2512-2520

12. Schlosser T, Konorza T, Hunold P, Kuhl H, Schmermund A, Barkhausen J (2004) Noninvasive visualization of coronary artery bypass grafts using 16-detector row computed tomography. J Am Coll Cardiol 44:1224-1229

13. Martuscelli E, Romagnoli A, D'Eliseo A, Tomassini M, Razzini C, Sperandio M, Simonetti G, Romeo F, Mehta JL (2004) Evaluation of venous and arterial conduit patency by 16-slice spiral computed tomography. Circulation 110:3234-3238

14. Khan MF, Herzog C, Landenberger K, Maataoui A, Martens S, Ackermann H, Moritz A, Vogl TJ (2005) Visualisation of noninvasive coronary bypass imaging: 4-row vs. 16-row multidetector computed tomography. Eur Radiol 15:118-126

15. Andreini D, Pontone G, Ballerini G, Bertella E, Nobili E, Parolari A, Pepi M (2007) Bypass graft and native postanastomotic coronary artery patency: assessment with computed tomography. Ann Thorac Surg 83:1672-1678

16. Salm LP, Bax JJ, Jukema JW, Schuijf JD, Vliegen HW, Lamb HJ, van der Wall EE, de Roos A (2005) Comprehensive assessment of patients after coronary artery bypass grafting by 16-detector-row computed tomography. Am Heart J 150:775-781

17. Hamon M, Lepage O, Malagutti P, Riddell JW, Morello R, Agostini D, Hamon M (2008) Diagnostic performance of 16and 64-section spiral CT for coronary artery bypass graft assessment: meta-analysis. Radiology 247:679-686

18. Nazeri I, Shahabi P, Tehrai M, Sharif-Kashani B, Nazeri A (2009) Assessment of patients after coronary artery bypass grafting using 64-slice computed tomography. Am J Cardiol 103:667-673

19. Hein PA, May J, Rogalla P, Butler C, Hamm B, Lembcke A (2010) Feasibility of contrast material volume reduction in coronary artery imaging using 320-slice volume CT. Eur Radiol 20:13371343

20. de Graaf FR, Schuijf JD, van Velzen JE, Kroft LJ, de Roos A, Reiber JH, Boersma E, Schalij MJ, Spano F, Jukema JW, van der Wall EE, Bax JJ (2010) Diagnostic accuracy of 320-row multidetector computed tomography coronary angiography in the noninvasive evaluation of significant coronary artery disease. Eur Heart J 31:1908-1915

21. Dewey M, Zimmermann E, Deissenrieder F, Laule M, Dubel HP, Schlattmann P, Knebel F, Rutsch W, Hamm B (2009) Noninvasive coronary angiography by 320-row computed tomography with lower radiation exposure and maintained diagnostic accuracy: comparison of results with cardiac catheterization in a head-tohead pilot investigation. Circulation 120:867-875 
22. de Graaf FR, Schuijf JD, van Velzen JE, Boogers MJ, Kroft LJ, de Roos A, Reiber JH, Sieders A, Spano F, Jukema JW, Schalij MJ, van der Wall EE, Bax JJ (2010) Diagnostic accuracy of 320-row multidetector computed tomography coronary angiography to noninvasively assess in-stent restenosis. Invest Radiol 45:331-340

23. Vahanian A, Alfieri O, Al-Attar N, Antunes M, Bax J, Cormier B, Cribier A, de JP, Fournial G, Kappetein AP, Kovac J, Ludgate S, Maisano F, Moat N, Mohr F, Nataf P, Pierard L, Pomar JL, Schofer J, Tornos P, Tuzcu M, van Hout B, von Segesser LK, Walther T (2008) Transcatheter valve implantation for patients with aortic stenosis: a position statement from the European Association of Cardio-Thoracic Surgery (EACTS) and the European Society of Cardiology (ESC), in collaboration with the European Association of Percutaneous Cardiovascular Interventions (EAPCI). Eur Heart J 29:1463-1470

24. Calkins H, Brugada J, Packer DL, Cappato R, Chen SA, Crijns HJ, Damiano RJ Jr, Davies DW, Haines DE, Haissaguerre M, Iesaka Y, Jackman W, Jais P, Kottkamp H, Kuck KH, Lindsay BD, Marchlinski FE, McCarthy PM, Mont JL, Morady F, Nademanee K, Natale A, Pappone C, Prystowsky E, Raviele A, Ruskin JN, Shemin RJ (2007) HRS/EHRA/ECAS expert Consensus Statement on catheter and surgical ablation of atrial fibrillation: recommendations for personnel, policy, procedures and followup. A report of the Heart Rhythm Society (HRS) Task Force on catheter and surgical ablation of atrial fibrillation. Heart Rhythm 4:816-861

25. Delgado V, Ng AC, van de Veire NR, van der Kley F, Schuijf JD, Tops LF, de WA, Tavilla G, de Roos A, Kroft LJ, Schalij MJ, Bax JJ (2010) Transcatheter aortic valve implantation: role of multidetector row computed tomography to evaluate prosthesis positioning and deployment in relation to valve function. Eur Heart $\mathrm{J}$ 31:1114-1123

26. den Uijl DW, Tops LF, Delgado V, Schuijf JD, Kroft LJ, de Roos A, Boersma E, Trines SA, Zeppenfeld K, Schalij MJ, Bax JJ (2011) Effect of pulmonary vein anatomy and left atrial dimensions on outcome of circumferential radiofrequency catheter ablation for atrial fibrillation. Am J Cardiol 107:243-249

27. Valentin J (2007) Managing patient dose in multi-detector computed tomography (MDCT). ICRP Publication 102. Ann ICRP 37:1-79

28. Raff GL, Abidov A, Achenbach S, Berman DS, Boxt LM, Budoff MJ, Cheng V, DeFrance T, Hellinger JC, Karlsberg RP (2009) SCCT guidelines for the interpretation and reporting of coronary computed tomographic angiography. J Cardiovasc Comput Tomogr 3:122-136

29. Reiber JH, van der Zwet PM, Koning G, von Land CD, van Meurs B, Gerbrands JJ, Buis B, van Voorthuisen AE (1993) Accuracy and precision of quantitative digital coronary arteriography: observer-, short-, and medium-term variabilities. Cathet Cardiovasc Diagn 28:187-198

30. Reiber JH, Jukema W, van Boven A, van Houdt RM, Lie KI, Bruschke AV (1994) Catheter sizes for quantitative coronary arteriography. Cathet Cardiovasc Diagn 33:153-155

31. Romagnoli A, Patrei A, Mancini A, Arganini C, Vanni S, Sperandio M, Simonetti G (2010) Diagnostic accuracy of 64slice CT in evaluating coronary artery bypass grafts and of the native coronary arteries. Radiol Med 115:1167-1178

32. Ropers D, Pohle FK, Kuettner A, Pflederer T, Anders K, Daniel WG, Bautz W, Baum U, Achenbach S (2006) Diagnostic accuracy of noninvasive coronary angiography in patients after bypass surgery using 64-slice spiral computed tomography with 330-ms gantry rotation. Circulation 114:2334-2341

33. Malagutti $\mathrm{P}$, Nieman K, Meijboom WB, van Mieghem CA, Pugliese F, Cademartiri F, Mollet NR, Boersma E, de Jaegere PP, de Feyter PJ (2007) Use of 64-slice CT in symptomatic patients after coronary bypass surgery: evaluation of grafts and coronary arteries. Eur Heart J 28:1879-1885

34. Auguadro C, Manfredi M, Scalise F, Mustica T, Vanoli E, Khouri T, Specchia G (2009) Multislice computed tomography for the evaluation of coronary bypass grafts and native coronary arteries: comparison with traditional angiography. J Cardiovasc Med 10:454-460

35. Weustink AC, Nieman K, Pugliese F, Mollet NR, Meijboom WB, Van MC, ten Kate GJ, Cademartiri F, Krestin GP, de Feyter PJ (2009) Diagnostic accuracy of computed tomography angiography in patients after bypass grafting: comparison with invasive coronary angiography. JACC Cardiovasc Imaging 2:816-824

36. Einstein AJ, Elliston CD, Arai AE, Chen MY, Mather R, Pearson GD, Delapaz RL, Nickoloff E, Dutta A, Brenner DJ (2010) Radiation dose from single-heartbeat coronary CT angiography performed with a 320-detector row volume scanner. Radiology 254:698-706

37. Steigner ML, Otero HJ, Cai T, Mitsouras D, Nallamshetty L, Whitmore AG, Ersoy H, Levit NA, Di Carli MF, Rybicki FJ (2009) Narrowing the phase window width in prospectively ECGgated single heart beat 320-detector row coronary CT angiography. Int J Cardiovasc Imaging 25:85-90

38. Herzog BA, Wyss CA, Husmann L, Gaemperli O, Valenta I, Treyer V, Landmesser U, Kaufmann PA (2009) First head-to-head comparison of effective radiation dose from low-dose 64-slice CT with prospective ECG-triggering versus invasive coronary angiography. Heart 95:1656-1661

39. Dewey M, Zimmermann E, Laule M, Rutsch W, Hamm B (2008) Three-vessel coronary artery disease examined with 320-slice computed tomography coronary angiography. Eur Heart J 29:1669

40. Lell M, Marwan M, Schepis T, Pflederer T, Anders K, Flohr T, Allmendinger T, Kalender W, Ertel D, Thierfelder C, Kuettner A, Ropers D, Daniel WG, Achenbach S (2009) Prospectively ECGtriggered high-pitch spiral acquisition for coronary CT angiography using dual source CT: technique and initial experience. Eur Radiol 19:2576-2583

41. Goetti R, Feuchtner G, Stolzmann P, Desbiolles L, Fischer MA, Karlo C, Baumueller S, Scheffel H, Alkadhi H, Leschka S (2010) High-pitch dual-source CT coronary angiography: systolic data acquisition at high heart rates. Eur Radiol 20:2565-2571

42. Cooper WA, O'Brien SM, Thourani VH, Guyton RA, Bridges CR, Szczech LA, Petersen R, Peterson ED (2006) Impact of renal dysfunction on outcomes of coronary artery bypass surgery: results from the Society of Thoracic Surgeons National Adult Cardiac Database. Circulation 113:1063-1070

43. Yamamoto M, Kimura F, Niinami H, Suda Y, Ueno E, Takeuchi $Y$ (2006) Noninvasive assessment of off-pump coronary artery bypass surgery by 16-channel multidetector-row computed tomography. Ann Thorac Surg 81:820-827

44. Maluenda G, Goldstein MA, Lemesle G, Weissman G, Weigold G, Landsman MJ, Hill PC, Pita F, Corso PJ, Boyce SW, Pichard AD, Waksman R, Taylor AJ (2010) Perioperative outcomes in reoperative cardiac surgery guided by cardiac multidetector computed tomographic angiography. Am Heart J 159:301-306

45. Ketelsen D, Luetkhoff MH, Thomas C, Werner M, Buchgeister M, Tsiflikas I, Reimann A, Burgstahler C, Kopp AF, Claussen CD, Heuschmid M (2009) Estimation of the radiation exposure of a chest pain protocol with ECG-gating in dual-source computed tomography. Eur Radiol 19:37-41

46. Achenbach S, Marwan M, Ropers D, Schepis T, Pflederer T, Anders K, Kuettner A, Daniel WG, Uder M, Lell MM (2010) Coronary computed tomography angiography with a consistent dose below $1 \mathrm{mSv}$ using prospectively electrocardiogramtriggered high-pitch spiral acquisition. Eur Heart J 31:340-346 